\title{
Sustainability Risk for Global Production Networks in the Automobile Industry: A Case of Supplier Networks
}

\author{
Jakob E. Beer* and Jayantha P. Liyanage \\ University of Stavanger, Norway \\ \{jakob.e.beer,j.p.liyanage\}@uis.no
}

\begin{abstract}
Sustainability risk for global production networks can be considered more important than ever due to its distributed nature. The automobile industry relies heavily on its global supply networks. Nevertheless, little is being done to improve the sustainability of complex production environments. In practice, there is a number of factors that regulate the sustainability risk in any industry, and this paper pays special attention on how flexibility requirements can help mitigate sustainability risk by reducing the chance of unnecessary supply noncompliance performance.
\end{abstract}

Keywords: manufacturing networks, sustainability risk, automobile industry, production, capacity, flexibility.

\section{Introduction}

The emergence of low cost supply markets such as China, East Europe, and Mexico has made already globally spanning production networks even more complex, and amplified sensitivity towards reactions and overreactions [1]. In a permanent effort to reach economic efficiency and due to the visible increase of suppliers' competencies, there have been some changes concerning the distribution of value-added throughout production networks. The reasons for this development are diverse, cf. [2-5]. Task division and outsourcing decisions do not only involve peripheral business activities but often times concern core competencies as well [6].

There is some consensus that production networks have become more vulnerable with rising complexity $[7,8]$. The complexity of cars, however, requires that car producers rely on multiple partners to manage the development and production of cars in a timely and economic fashion. The consequence is that success is more about how well networks perform rather than about an individual OEM's performance [9]. At the same time, globally distributed production bears some important implications regarding both ecological and social aspects. Transportation between different continents is quite energy intense; and efficiency improvements - from the OEM's point of view such as just-in-time or just-in-sequence delivery have increased traffic congestion with all the known related consequences for the natural and social environment.

\footnotetext{
* Corresponding author.
} 
The consequence of all of the above is that globally acting production networks are necessary, yet problematic. For OEMs, they provide economic advantages - especially if operations run smoothly. For the public in supplier countries, they provide welfare. For the nature, though, they have inherent negative effects. And in case of unforeseen interruptions, the bottom line of some global sourcing decisions can easily turn red and switching the transportation mode to air to speed up operations further worsens the ecological balance. The goal must therefore be to reduce the chance of noncompliance performance in global production networks to keep the risk of adverse effect on the economic outcome, the public, and the natural environment - i.e., to keep sustainability risks - as low as possible.

For several types of supply chain risks, flexibility represents an adequate approach to mitigate the negative impact in case of the occurrence of unfavorable incidents [10]. This paper is to contribute to this objective by highlighting flexibility agreements between OEMs and suppliers as one cause for sustainability risks in global automotive production networks and by introducing one approach to help mitigate sustainability risks.

\section{Methodology}

To understand the implications of flexibility agreements and to determine how flexibility agreements can be used to enhance the functionality of production networks, information from logistics and supply management experts from both car makers and suppliers have been collected through a round of 28 interviews, involving five European and American OEMs and six European suppliers.

The questions aimed at the link between OEMs and tier-1 suppliers, so for OEMs all questions were related to the supply side while for suppliers most questions were related to the demand site. The data covered the general capacity planning process, the importance of the capacity planning process in terms of management attention, transparency about capacity planning strategies of competitors, known weaknesses of the planning approach, and the effect of the global economic crisis and the subsequent boom on the capacity planning strategy. The interviews were conducted either faceto-face or on the phone, mostly by two interviewers, and took 40 to 150 minutes. Most interview partners were involved in supplier management and came from one OEM, but also several management positions of other OEMs and suppliers could be covered. 17 of the 28 interview partners were regular supplier management specialists while 11 interview partners were ranked manager, senior manager, director, or higher.

The purpose of the interviews was to get a better understanding of the general supply capacity planning process as well as to identify weaknesses of the common approaches. The data has not been used for statistical evaluation.

In addition to the interviews, information has been obtained from the day-to-day business in supplier management and from the review of some relevant literature and several automobile industry information services. 


\section{Status Quo Review}

\subsection{Supply Shortages}

The 2008/2009 crisis left many suppliers behind with largely unused capacity and high inventories, particularly with those parts that have long production and delivery lead times. Several suppliers along the whole supply chain had to close production plants. When demand for automobiles started to recover in early 2010 , the remaining inventories were used up quite fast, and supply shortages for several parts loomed ahead. Part shortages became a major concern in the industry on a global basis throughout 2010 and 2011. Several car and truck makers had to halt production for several days, sometimes for a week [11-14]. The situation has eased in 2012 with suppliers having been able to set up the required production capacities and strong demand downturn in several countries (e.g., due to the recurrence of the European debt crisis).

One reason for the severity of the supply situation can certainly be seen in the industry leaders' effort to streamline their supply networks according to lean principles with low inventories, just-in-time or just-in-sequence deliveries, and mainly singlesourcing. In an interview, the director of supply chain management of the European division of an American car maker stated that his company does experience more shortages these days than it did in the 1990s before they started streamlining their networks.

The causes previously mentioned had led to the situation where OEMs competed for the scarce resource of supplier production capacity while many suppliers were running extra working shifts. The negative consequences were manifold: Frequent express deliveries by airplane, helicopter, and light trucks have been conducted - with obviously severe implications for the natural environment and for the financial results. Quality problems due to tool overutilization, skipped machine maintenance, and skipped quality control by suppliers have been experienced, which, of course, worsened the situation as capacity was wasted when parts were rejected. On the other hand, supplied parts with impaired quality that usually would have been rejected have been approved and accepted in some cases, which raises ethical questions with regard to the end customer. Some OEMs increased their pressure on suppliers to an extent that made suppliers use resources "reserved" for other OEMs to meet the demand of that OEM, which also raises ethical as well as legal questions. From some suppliers in East Europe, bribe of customs officials to speed up the border crossing process, which, again, is both an ethical and legal topic. When sustainability is one goal of responsibly acting organizations, then the points mentioned above represent sustainability risks deriving from situations of supply shortage.

\subsection{Supply Networks and Supply Chains}

The supply chain model has become quite popular during the course of the last two decades. Nevertheless, the model is rather incomplete [15] and the term 'supply chain' to some extent misleading. The automobile industry is characterized by a complex web of both vertical and lateral interrelations [16, 17]. Accordingly, lateral effects can affect organizational performance, which is not taken into account in a 
linear supply chain model [1]. Hence, a focus on supply chains might distract supply management professionals from lateral performance impact. The consequences can be manifold, and there is good reason to reconsider underlying assumptions in supply management, particularly when it comes to supplier capacity planning and thus to the question of standard production flexibility [18].

\section{$4 \quad$ Results and Analysis}

Research suggests that the problems outlined above do not simply happen to happen due to suppliers' operational weaknesses but can rather be traced back to certain constellations on the OEM side that inherently bear the chance of unfavourable results. The items described below represent sources of supplier non-compliance performance that apply to the OEMs which were part of the study and may equally apply to other companies in this industry and other industries.

\subsection{Capacity Planning}

Supplier production capacity is determined around 24 to 36 months prior to start of production. This implies that capacity may be planned under very different economic circumstances than there will be once the production is going to get ramped up. For car models that are launched in late 2010 or in 2011, capacities may have been planned in the middle of the global economic crisis with generally lower sales expectations while demand for these models might be booming today.

\subsection{Capacity Flexibility}

When OEMs source production of certain assembly components to a supplier, they generally require the supplier to provide a certain amount of production capacity flexibility. It is obvious that supply networks often need to commit excess resources to production to ensure timely responses to the market since planned production quantities usually are based on forecasts instead of actual demand. Other arguments for paying particular attention to production capacity flexibility are, for example, a decreasing level of professionalism upstream the supply chains, the vulnerability of the automotive industry with respect to economic downturns, the threat of bullwhip effects, the decreasing level of transparency upstream the supply chain with respect to forecasted demand data, differences in data processing with different time horizons for forecasts and call-offs along the supply chain, and an increasing time lag between action and reaction with increasing length of the supply chain [18].

While there is broad consensus that some kind of flexibility agreement is necessary, there are different opinions on how much flexibility suppliers should be required to provide since flexibility - which basically is excess capacity - is expensive. Tang and Tomlin [10] point out that the benefit obtained by a certain flexibility level in most cases is represented by a concave function, which means that significant impact can be achieved with little adjustment in flexibility. It is therefore remarkable that 
capacity flexibility agreements between most OEMs and suppliers are not particularly sophisticated and do not take into account the different characteristics of parts. In fact, all interviewed OEMs require the same production capacity flexibility for all parts they source to suppliers, regardless of part characteristics, contracted volumes or whatsoever. Simply put: They employ a "one size fits all" approach. This approach has led to several problems in the past and yet seems to be widely accepted. The interviewed suppliers state that also other OEMs who have not been covered in this study employ the same approach. Those agreements usually include a required flexibility between $10-20 \%$ (depending on the OEM) and a timeframe within which the production output hike has to be reached, e.g. seven days.

\section{$5 \quad$ Mitigating Measures}

Generally, it is economically efficient for all partners when suppliers can reach high machine utilization while being performance compliant. Regarding forecast uncertainty, network effects, and volatile demand, this cannot always be the case, though. One way to reduce the chance of supplier non-compliance performance and thus to mitigate sustainability risks is to reconsider flexibility agreements with regard to the characteristics of the parts sourced. For this purpose, a set of criteria will be introduced that can be utilized to determine what assembly parts OEMs should require suppliers to provide higher capacity flexibility for.

\subsection{Criteria for Higher Flexibility}

One result of the research (among others that can be found in 18) was a set of criteria that can be used to identify those assembly parts for which OEMs should require suppliers to provide higher production capacity flexibility. The list can be divided into one group of factors that really points out the need to adjust flexibility and another group of factors that support the decision, i.e. how fast the supply network could react to unexpectedly high demand and how expensive it would be. Those factors could be considered "amplifiers" for the problem. Clearly, requiring higher flexibility would increase upfront costs of suppliers for setting up excess capacity, and thus leads to higher procurement costs; there is some reason to assume, however, that the benefits of lower sustainability risks would overcompensate for higher procurement prices and thus lead to increased production network sustainability. It is likely to be beneficial to require higher-than-usual capacity flexibility when the following criteria hold true:

The Uncertainty of the Forecasted Take Rate Is High. When parts are innovations, i.e. extra equipment that are new to the market, and there is no actual experience how well the extra equipment will be embraced by customers, it is harder to determine an accurate estimation of the take rate. Take rates for innovative extra equipments proved to be hard to predict. There are various cases of parts for which forecasted take rates were far away from actual sales, which eventually led to capacity shortages. 
It should therefore be taken into consideration if the forecasted take rate can be expected to be rather accurate as it is based on past experience with the same or similar products or if it is more speculative as the extra equipment represents an innovation.

The Sales Forecast of the Car Model Is Uncertain. Of course, it may be the case that the sales forecast of a certain car model as such is highly uncertain. In particular, this applies to models that fill a niche or create a new market segment. When Mercedes-Benz, for example, introduced the R-Class, forecasted sales were much higher than they finally turned out to be. This may also apply to particularly expensive cars as their demand is more vulnerable to the global economic situation. Sales of the S-Class in 2011, for example, were much higher than it was expected, yet were severely affected by the global recession in 2008 and 2009. Parts that are used for only one car model may deviate faster from the predicted volumes than parts that are used in several models due to the risk pooling effect. This is particularly true when the one car model into which the component is built has very volatile demand itself.

The Part Is Sourced to a Single Supplier. If the assembly part is sourced to a single supplier, this supplier will need to provide higher capacity flexibility than it will need as only one of multiple supply sources. With dual or multiple sourcing, increases in demand can be balanced among suppliers while a single-source supplier would need to provide "full" flexibility to meet demand.

The Assembly Line Is Shared with Other OEMs. When the assembly line is shared with other OEMs, the available remaining capacity does not only depend on one's own demand but also on other parties' demand. In many market segments, there are products from different OEMs that aim at the same customers. Increasing and decreasing market volume thus potentially affects several customers that are supplied from the same assembly line. When demand for luxury cars booms - which has been the case since 2010 - then not only are more Mercedes-Benz E-Class cars sold but also more of Audi's A6 and BMW's 5 Series. On a shared assembly line, all customers affect each other in terms of available production capacity. Requiring the supplier to have additional production capacity available on short call can help avoiding capacity shortages for one's own parts as otherwise the danger is evident that available excess capacity is used up by competing customers. In general, network effects should be taken into account when determining the required production capacity flexibility. Particularly strong network effects suggest a need for higher flexibility.

The Profit Margin of the Extra Equipment Is High. Especially in the luxury segment, profit margins of some extra equipment are particularly high - sometimes several hundred percent. Parts with particularly high profit margins may open the chance to secure supply with higher production capacity flexibility rather than those parts that hardly deliver profit. Additionally, in the luxury segment higher procurement costs due to higher flexibility may be compensated by higher prices that customers are charged - either directly through higher prices for the extra equipment or indirectly through bundling the extra equipment with additional extra equipment the customer has to pay for. 
The Time Necessary to Set Up Additional Capacities Is High. When setting up additional capacity in case of tight production capacity takes particularly long, it is risky to plan very lean - especially when forecasted demands are uncertain (see above). Setting up additional production capacity can easily take several months in some industries. Requiring those suppliers to install excess production capacity to secure a certain amount of flexibility may justify higher upfront costs when part shortages can by avoiding long lead time for additional capacity.

\section{Costs for Setting Up Additional Capacity within a Short Period of Time to Meet} Higher Demand Are High. It may happen that the costs for higher flexibility are low when it is considered right from the beginning. In some situations, it may happen, though, that adding capacity in a later point in time during the series production process is accompanied by high cost as assembly lines or material flow has to be reconfigured. Adding a second assembly line on a green field may be cheap, but moving equipment around to place additional machines may come along with the need to interrupt the production process for some time. Setting up additional machines during the series production process may require major changes in the factory layout. Sometimes, setting up additional machines may be less problematic, but having them set up within a short period of time can be expensive, for instance, when this needs to be achieved through express orders of tools and machines in order to avoid long lead time.

Air Traffic Is Necessary for Express Deliveries in Case of Supply Shortage. If supply shortages emerge, usually transportation time is to be reduced with express deliveries in order to avoid production interruptions. In case of suppliers being located in distant places, air traffic frequently replaces maritime or road traffic. This, however, adversely affects the environmental and economic sustainability of the production network.

\subsection{Evaluation}

Companies are reluctant to invest in flexibility as they are lacking a clear understanding of the benefits [10]. A simple simulation model might help to demonstrate the effect of lump sum standard flexibility

The model would need to incorporate two random input variables - the number of cars sold and the take rate - along with other parameters such as forecasted car sales and forecasted take rate. Also, "amplifying factors" can be defined as input variables based on whether or not costs for excess capacity are high, air traffic would be necessary, and so forth. The decision variable is the flexibility rate suppliers are required to provide. The output would be an analysis as to what extent actual demand for the assembly component exceeds production capacity including the reserved flexibility (cf. Fig. 1). 


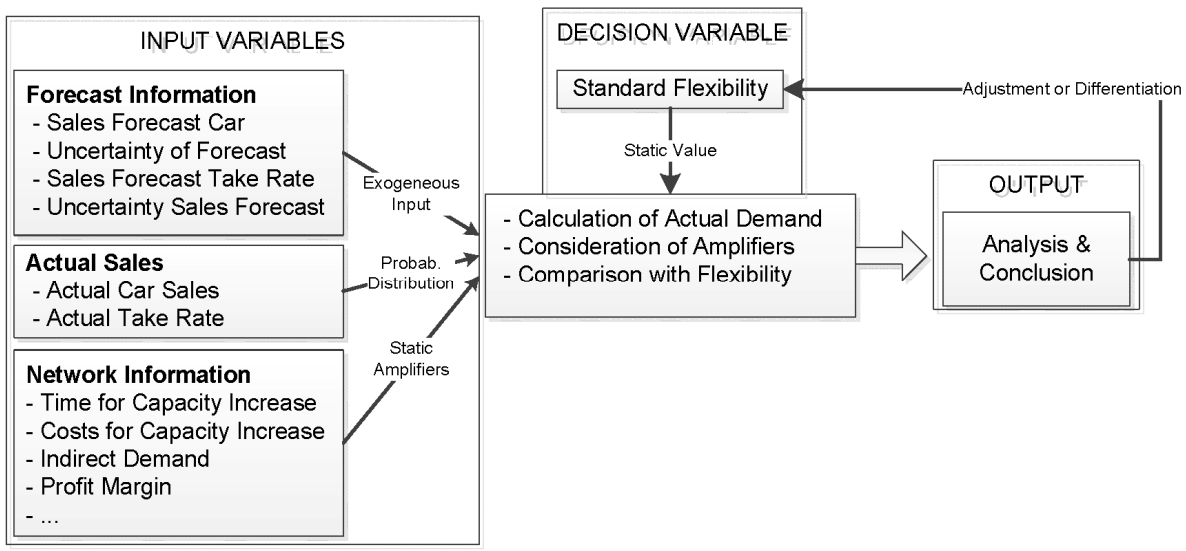

Fig. 1. Evaluation Framework

Such a model can easily be built as with any common discrete simulation tool and even with a spreadsheet and macros, e.g., as Monte Carlo simulation model. Network effects can be included and awareness for lateral performance impact can thereby be increased. This simple model cannot prove or predict any particular supply situation development (though the link with real life date can be created to make the model more realistic); its main purpose shall be the demonstration as to how fast a lump sum flexibility approach can result into supply shortage if assumptions sales forecasts are based on do not hold true.

\section{Conclusion}

This paper discusses the situation of frequent supply shortages in the automobile industry in 2010 and 2011. Based on research in the automobile industry, including expert interviews, the paper suggests that certain structural weaknesses in the supplier production capacity planning process have contributed to the severity of the supply situation, involving different sustainability risks. It has been argued that in many cases supply shortages will eventually lead to significant adverse effects for society and environment.

Hence, to improve the supplier production capacity planning process and thus to mitigate sustainability risks a set of criteria has been defined and explained. These criteria are to support the identification of those assembly parts of an automobile that shall be produced with higher production capacity flexibility. Assembly parts for which one or more of these criteria hold true, it seems inadequate to use the traditional lump sum standard production capacity flexibility approach.

The concept shows how diligent judgement of characteristics of sourcing relations can be used to improve on sustainability by helping to avoid unnecessary supply shortages. 


\section{References}

1. Waldraff, A.: Dynamische Aspekte komplexer Logistiksysteme. In: Garcia Sanz, F.J. (ed.) Die Automobilindustrie auf dem Weg zur Globalen Netzwerkkompetenz. Effiziente und flexible Supply Chains erfolgreich gestalten, pp. 161-180. Springer, Heidelberg (2007)

2. Blanco, E.E.: Stay Ahead of the GHG Curve. Inside Supply Management 22(3), 32-33 (2011)

3. Holweg, M.: The Evolution of Competition in the Automobile Industry. In: Parry, G., Graves, A. (eds.) Build to Order. The Road to the 5-Day Car, pp. 13-34. Springer, London (2008)

4. Rennemann, T.: Logistische Lieferantenauswahl in globalen Produktionsnetzwerken, 1st edn. Rahmenbedingungen, Aufbau und Praxisanwendung eines kennzahlenbasierten Entscheidungsmodells am Beispiel der Automobilindustrie. Deutscher Universitäts-Verlag I GWV Fachverlage GmbH, Wiesbaden (2007)

5. Semmler, K., Mahler, D.: Von Beschaffung zum Wertschöpfungsmanagement - Gestaltungsdimensionen einer Funktion im Wandel. In: Garcia Sanz, F.J. (ed.) Die Automobilindustrie auf dem Weg zur Globalen Netzwerkkompetenz. Effiziente und flexible Supply Chains erfolgreich gestalten, pp. 25-48. Springer, Heidelberg (2007)

6. Roehrich, J.K.: Outsourcing: Management and Practice Within the Automotive Industry. In: Parry, G., Graves, A. (eds.) Build to Order. The Road to the 5-Day Car, pp. 75-97. Springer, London (2008)

7. Christopher, M., Peck, H.: Building the Resilient Supply Chain (2005)

8. Ritschie, B., Brindley, C.: Effective Management of Supply Chains: Risks and Performance. In: Wu, T. (ed.) Managing Supply Chain Risk and Vulnerability. Tools and Methods for Supply Chain Decision Makers, pp. 9-28. Springer, London (2009)

9. Urban, G.: Das ganze Zuliefernetzwerk im Griff - Innovations- und Effizienzpotenziale nutzen. Von der Zulieferkette zum Zuliefernetzwerk. In: Gehr, F., Hellingrath, B. (eds.) Logistik in der Automobilindustrie. Innovatives Supply Chain Management für wettbewerbsfähige Zulieferstrukturen; mit 6 Tabellen, pp. 1-4. Springer, Heidelberg (2007)

10. Hardin, G.J.: The Tragedy of the Commons (1968)

11. AutomotiveWorld.com: Audi CEO highlights supplier concerns, Germany (2011)

12. Lampinen, M.: Parts shortage halts Chrysler plant, Canada (2011)

13. Priddle, A.: Lack of engines idles 3,000 Ford workers at Dearborn plant. The Detroit News (January 25, 2011), http: / / detnews. com/article/20110125/AUTO01/ 101250325/1148/auto01/Lack-of-engines-idles-3-000-Fordworkers-at-Dearborn-plant (accessed January 25, 2011)

14. Supplier Business Ltd.: Volvo output affected by delayed component supply. Demand to further increase in European and North American market (2011)

15. Johnsen, T.E., Lamming, R.C., Harland, C.M.: Inter-Organizational Relationships, Chains, and Networks. A Supply Perspective. In: Cropper, S., Ebers, M., Huxham, C., Smith Ring, P. (eds.) The Oxford Handbook of Inter-Organizational Relations. Oxford handbooks, pp. 61-89. Oxford University Press, Oxford (2008)

16. Hensel, J.: Netzwerkmanagement in der Automobilindustrie. Erfolgsfaktoren und Gestaltungsfelder. Deutscher Universitäts-Verlag I GWV Fachverlage GmbH, Wiesbaden (2007)

17. Schonert, T.: Interorganisationale Wertschöpfungsnetzwerke in der deutschen Automobilindustrie. Die Ausgestaltung von Geschäftsbeziehungen am Beispiel internationaler Standortentscheidungen, 1st edn. Entscheidungs- und Organisationstheorie, Gabler, Wiesbaden (2008)

18. Beer, J.E., Schumacher, T., Liyanage, J.P.: Network Performance Impact on Supply Reliability in the Automobile Industry. Submitted to Portland International Conference on Management of Engineering \& Technology (PICMET), Vancouver, CA, July 29-August 2 (2012) 